\title{
Anatomy of the Frontal Gland and Ultramorphology of the Frontal Tube in the Soldier Caste of Species of Nasutitermitinae (Isoptera, Termitidae)
}

\author{
CONCEICAO A. SANTOS ${ }^{1^{*}}$ AND ANA M. COSTA-LEONARDO ${ }^{2}$ \\ ${ }^{1}$ Universidade Federal de Viçosa, Centro de Ciências Biológicas e da Saúde, Depto. de Biologia Geral. 36570-000 Viçosa, MG, Brazil \\ ${ }^{2}$ Instituto de Biociências-Universidade Estadual Paulista, CEP13506-900, Rio Caro, SP, Brazil
}

\author{
KEY WORDS Termites; exocrine gland; defense; nasute; morphology
}

\begin{abstract}
All termite species (Isoptera) are eusocial. These insects live in societies where the division of labor is a predominant characteristic, conditioned by the presence of castes with different morphology, ontogeny, and development. The soldier caste is unique among social insects and it is responsible for colony defense. Soldiers belonging to the Nasutitermitinae subfamily are very peculiar, since they may be polymorphic and present a nasus in addition to either developed or vestigial mandibles. The defensive secretions of soldiers of the neotropical Nasutitermitinae have been the aim of several chemical studies, but few data exist concerning the anatomy and histology of the exocrine glands. This article presents a comparative study on the anatomy of the frontal gland of soldiers of several Nasutitermitinae species: Syntermes dirus (Burmeister), Syntermes nanus (Constantino), Constrictotermes cyphergaster (Silvestri), Nasutitermes corniger (Motschulsky) and Velocitermes heteropterus (Silvestri), with emphasis on the ultramorphology and ultrastructure of the frontal tube. Microsc. Res. Tech. 69:913-918, 2006. @ 2006 Wiley-Liss, Inc.
\end{abstract}

\section{INTRODUCTION}

The division of labor is a predominant characteristic of the social system of the Isoptera, with each caste showing morphological adaptations related to their function (Noirot, 1969). According to Grassé (1986), termites are classified into seven families, with four of them being found in Brazil: Rhinotermitidae, Kalotermitidae, Serritermitidae, and Termitidae. The Termitidae are the most diverse, comprising four subfamilies: Macrotermitinae, Termitinae, Apicotermitinae, and Nasutitermitinae. Nevertheless, only the three latter subfamilies occur in Brazil (Constantino, 1999).

Roisin (2000) remarks that the presence of the soldier caste is the most characteristic autapomorphy of the Isoptera. This caste presents a sclerotized head with defensive structures and its development is always via a presoldier instar. Noirot and Darlington (2000) affirm that the soldier caste of termites is unique among the social insects because of its particular morphology, development, and behavior. These authors also emphasize that the soldiers never participate in the construction of the nest or in the collection of food and are not even able to feed by themselves; thus, it is possible that their role in trail deposition is a derived condition (Traniello and Beshers, 1985). In some species of termites, particularly those belonging to the families Termitidae, Rhinotermitidae, and Serritermitidae, the soldiers only receive liquid food and their gut is poorly developed, specially the hindgut (Noirot and Darlington, 2000).

Generally, the soldier originates from an undifferentiated larvae or worker and this transformation includes the development or alteration of certain organs, mainly muscles, defensive glands, cephalic capsule, and mandibles, as well as the disappearance of structures such as some mouth parts (Deligne et al., 1981). This transformation makes the soldiers quite different from the workers, specially the soldiers of the Nasutitermitinae, which show a frontal gland on the head and may also present a rather long and characteristic nasus (Miura and Matsumoto, 2000; Quennedey, 1984).

In these soldiers, known as nasutes, there is a rostrum that arises as a prolongation of the insect's head capsule. This nose might vary from a shallow cone open to a long tube, which corresponds to the frontal tube and has the function of expelling the secretion produced by the frontal gland (Costa-Leonardo, 1998, 2001; Costa-Leonardo and Barsotti, 1996; Costa-Leonardo and De Salvo, 1987; Fontes, 1987). According to Kriston et al. (1977), the soldier caste in the subfamily Nasutitermitinae is always peculiar and different from the other individuals of the colony, so much so that for Deligne et al. (1981), this caste is the most specialized among all the castes of social insects.

Fontes (1987) reports that the polymorphism of the Nasutitermitinae soldier can be observed in the variations in size and morphology, mainly with regard to the head. The soldiers of some Nasutitermitinae are polymorphic, representing two or three different sizes. In general, when two types of soldiers occur (dimorphic caste), one type is small because it originates from smaller workers, while the other type is large, less abundant, and derived from large workers (McMahan,

*Correspondence to: Conceicao A. Santos, Universidade Federal de Viçosa, Centro de Ciências Biológicas e da Saúde, Depto. de Biologia Geral., 36570-000 Viçosa-MG, Brazil. E-mail: casantos@insecta.ufv.br

Received 7 February 2006; accepted 7 July 2006

DOI 10.1002/jemt.20365

Published online 9 October 2006 in Wiley InterScience (www.interscience. wiley.com). 
1974; McMahan and Watson, 1975; Noirot, 1969). According to Noirot and Darlington (2000), this polymorphism appears to be frequently correlated to polyethism, but this issue is poorly explored in Isoptera.

The main exocrine glands of termite soldiers are the frontal gland, the sternal gland, the mandibular glands and the salivary glands. Numerous authors have devoted their studies to the chemical nature of the defensive secretions of the Isoptera (Deligne et al., 1981; Prestwich, 1979, 1983, 1988); however, the morphological and ethological data concerning the defense of termites are scarce and incomplete (Deligne et al., 1981; Quennedey, 1984), specially in regard to the Neotropical termites.

In view of these facts, this is a comparative study on the anatomy of the frontal gland of the soldier caste of some species of Nasutitermitinae, with emphasis on the ultramorphology and ultrastructure of the frontal tube.

\section{MATERIALS AND METHODS Insects}

Soldiers of the following species were used: Syntermes dirus, collected in Viçosa (Minas Gerais, Brazil), Constrictotermes cyphergaster, collected in Brasilia (DF, Brazil), Syntermes nanus, Nasutitermes corniger, and Velocitermes heteropterus, collected in Santa Rita do Passa Quatro (São Paulo State, Brazil).

\section{Anatomy}

The frontal gland of a soldier of $S$. dirus was drawn (Fig. 1) through the transparency of the integument with the aid of a camera lucida (o que siginfica) coupled to a stereomicroscope.

\section{Histology}

Inclusion in Paraffin. Whole soldiers of S. dirus (Fig. 2), and C. cyphergaster (Fig. 3) were fixed in Bouin, dehydrated in a standard alcohol series (7095\%), and included in paraffin.

Inclusion in Resin. Heads of the soldiers were fixed in $4 \%$ paraformaldehyde in sodium phosphate buffer. Next, the material was dehydrated in a standard ethanol series and embedded in $\mathrm{JB}_{4}$ infiltration resin. The histological sections from the material, included in resin or paraffin, were stained with hematoxylin and eosin and examined under a Zeiss photomicroscope.

Ultramorphology. Whole termite soldiers or isolated heads of $N$. corniger (Fig. 4) and V. heteropterus (Fig. 5) were used for this study. The material was first fixed in Karnovsky and dehydrated in a standard ethanol series (plus three 15-min baths in $100 \%$ ethanol). Next, the material was placed inside a mixture of alcohol and acetone (1:1), and finally, in pure acetone. Afterwards, the material was critical-point dried (Balzers CPD 030) for complete dehydration, fixed on an aluminum support, gold sputtered (Balzers SCD 050), and photographed using a scanning electron microscope (Jeol or Phillips).

Ultrastructure. For this analysis, the heads of soldiers of $V$. heteropterus (Fig. 6) were fixed in $2.5 \%$ glutaraldehyde in $0.1 \mathrm{M}$ cacodylate buffer, $\mathrm{pH} 7.4$, postfixed in $1 \%$ osmium tetroxide in the same buffer, dehy-

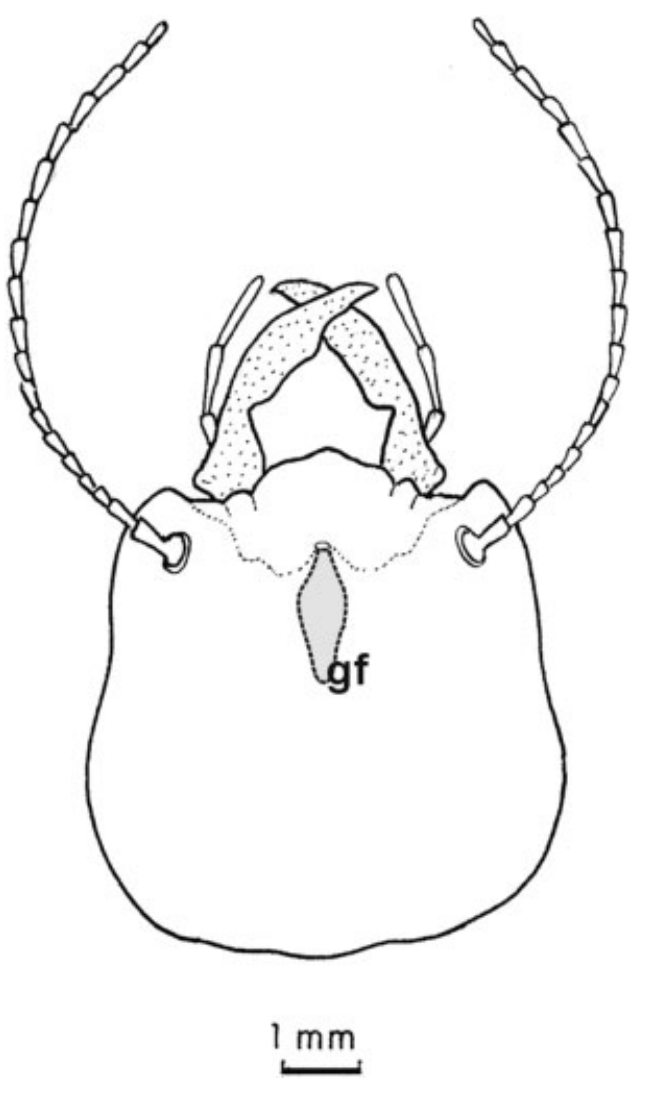

Fig. 1. Schematic representation of the frontal gland (gf) of a soldier of $S$. dirus.

drated in ethanol/acetone, and finally embedded in Epon/araldite resin. The sections were contrasted with uranyl acetate and lead citrate and observed and documented under a Zeiss transmission electron microscope.

\section{RESULTS}

The analysis of anatomical structure of the frontal gland in the $S$. dirus shows that the gland of these soldiers is sac-shaped, unpaired, and small in relation to the insect's head (Fig. 1).

The histological data confirm that the frontal gland consists of a simple sac formed by an epithelium of cylindrical cells (Fig. 2A). These cells expel their secretion into the glandular lumen, which also functions as a reservoir for the storage of the product. A tangential section of the gland shows the insertion of striated muscles, which appear to be in close contact with the glandular cells (Fig. 2B).

The cells of the glandular epithelium show elongated nuclei, apical brush borders that correspond to microvilli, and a thick apical cuticle (Fig. 2C). This epithelium is composed by type I cells according to the classification of Noirot and Quennedey $(1974,1991)$.

Unlike the mandibulate Syntermes, the histological sections of a nasute soldier with vestigial mandibles, as in the case of $C$. cyphergaster, confirm that the frontal gland is an unpaired structure that occupies most of the insect's head (Fig. 3A). The shape of the frontal 


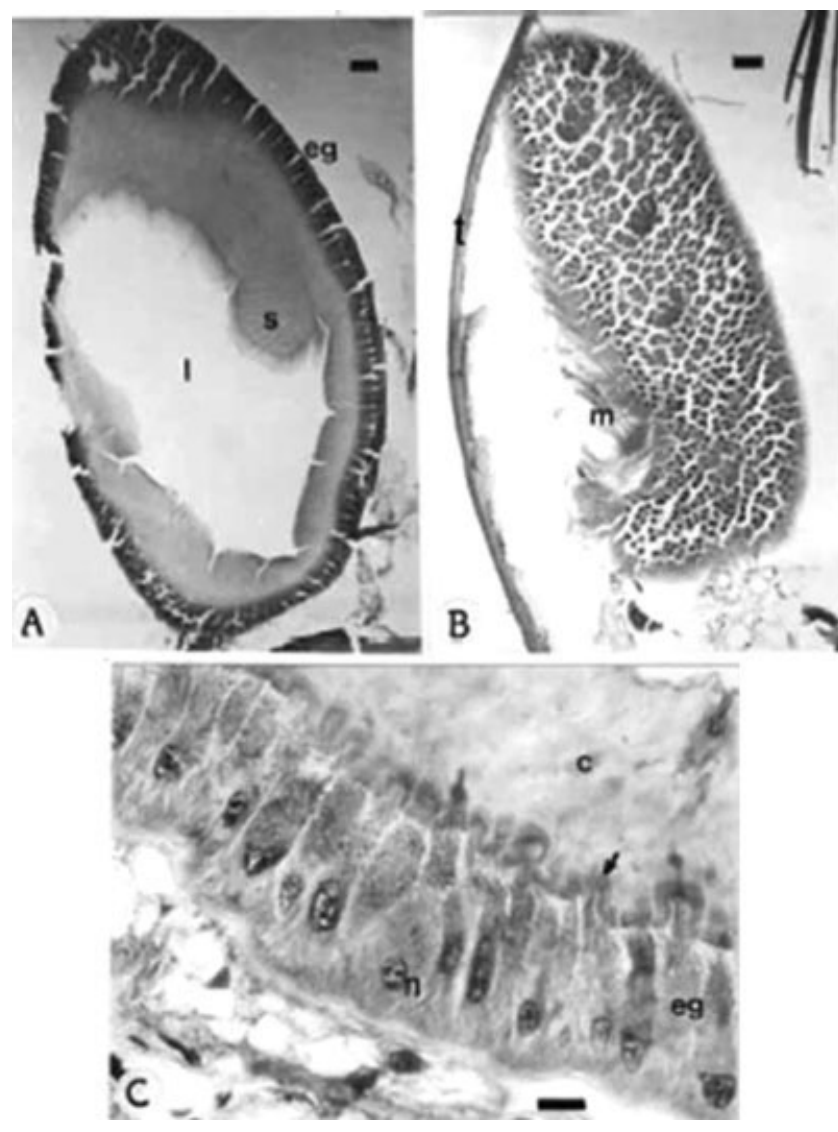

Fig. 2. (A) Longitudinal section of the frontal gland of a soldier of S. dirus. eg, glandular epithelium; l, glandular lumen; s, secretion (scale bar $=50 \mu \mathrm{m})$. (B) Longitudinal and tangential section of the frontal gland showing the striated muscle fibers $(\mathrm{m})$ associated to the secretory epithelium (scale bar $=50 \mu \mathrm{m}$ ). (C) Detail of the glandular epithelium (eg) in a soldier of $S$. dirus. Note the striated margin (arrow) that corresponds to the microvilli above the cells, as well as the thick apical cuticle (c). $\mathrm{n}$, nucleus (scale bar $=10 \mu \mathrm{m}$ ).

gland in this soldier resembles a vase with a wide base presenting a characteristic glandular epithelium. The neck of this vase forms a thin and elongated tube that penetrates the frontal tube and opens into the frontal pore or fontanella, which is the glandular opening (Fig. 3A). A thin layer of cells with apical chitin coat can be observed in the frontal tube (Fig. 3B). A welldeveloped muscle layer surrounds the frontal gland and is connected to the cephalic integument (Fig. 3A).

The head of a soldier of $N$. corniger is pear-shaped (Fig. 4A). In soldiers of this species, the end of the frontal tube presents a brown coloration, lighter than the rest of the nasus. A frontal pore is present at this end. At the end of the frontal pore, there are hairs that are probably sensory; four of these hairs are long and the others are shorter (Fig. 4B).

Glandular pores that correspond to the openings of glandular cells of type III are also present at the frontal tube (nasus) of the nasute soldiers (Figs. 4B, C, and 5B). Campaniform sensilla, which are mechanoreceptors, were also observed on this structure with scanning electron microscopy, as shown in Figure 4C.

In Velocitermes, which shows a trimorphic soldier caste, the frontal tube of the soldiers is adorned with


Fig. 3. (A) Sagittal section of the head of a soldier of $C$. cyphergaster evidencing the contorted shape of the gland $(*)$ and the associated musculature (m), which is connected to the cephalic integument. Note the secretory epithelium (arrow) located at the base of the gland (scale bar $=50 \mu \mathrm{m}$ ). (B) Longitudinal section of the frontal tube. pf, frontal pore (scale bar $=50 \mu \mathrm{m})$.

presented sensory hairs, sensilla, and glandular pores (Fig. 5). Ultrastructural sections of the frontal tube of the major soldier revealed an internal cuticular layer (Fig. 6) and that the cells that surround this cuticular ring produce secretions that are expelled into the lumen of this tube through cuticular ducts (Fig. 6B). These cells belong to class III according to the classification of Noirot and Quennedey $(1974,1991)$ and are evident in Figures 6A and B. These cells were characterized by the presence of strongly electron dense secretion vesicles (Fig. 6A) that appear empty (Fig. 6B) after expelling their secretory product.

\section{DISCUSSION}

According to Noirot and Quennedey (1991), the exocrine glands are structures specialized in the emission and storage of secretory products. Consequently, the glandular cells show a specific ability for the uptake of precursor molecules and the subsequent biosynthesis of a product, in addition to the effective regulation of the liberation of the secretion (Billen and Morgan, 1998).

When disturbed, the monomorphic soldiers of Syntermes secrete a clear liquid, which is expelled through the frontal pore of the short nasus. Termites of this genus are leaf-cutters and show crepuscular and noctur- 

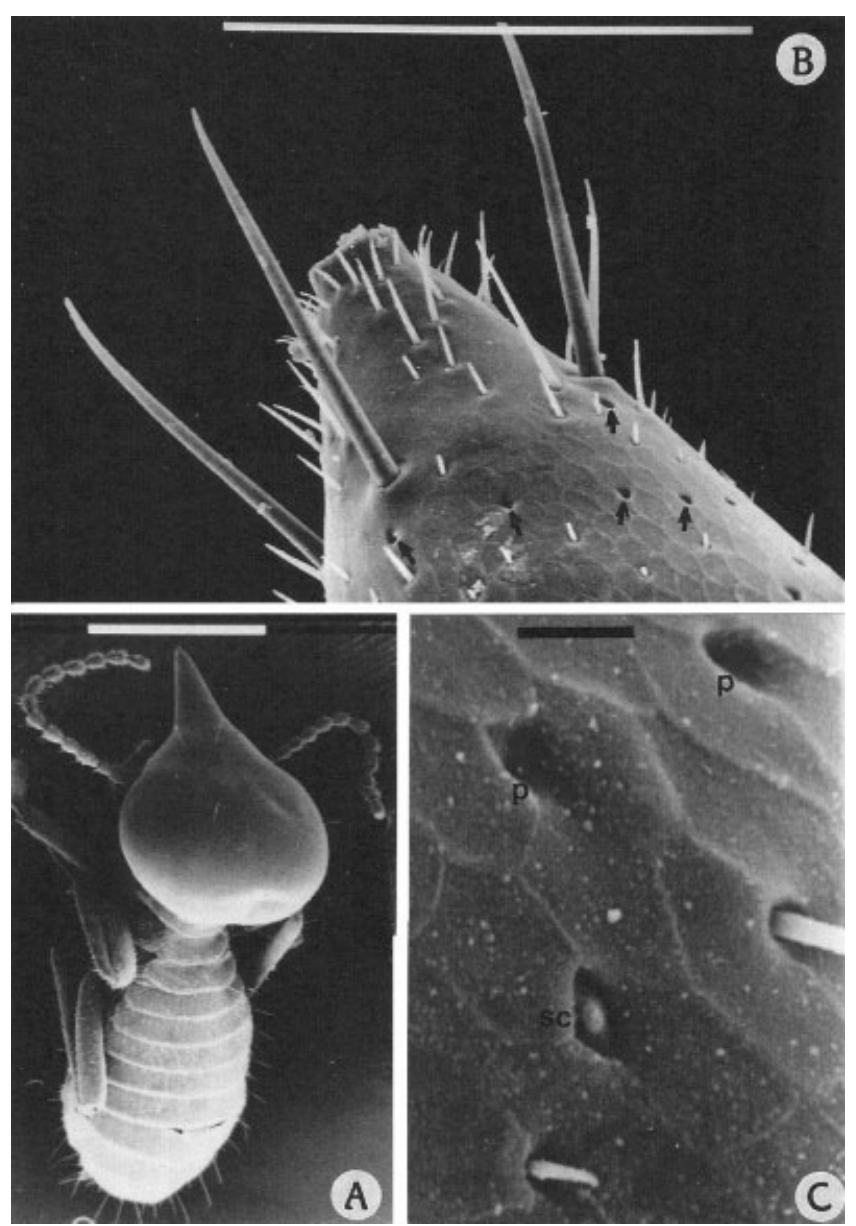

Fig. 4. (A) General view of a small soldier of Nasutitermes corniger evidencing the pear-shaped head (scale bar $=1 \mathrm{~mm}$ ). (B) Detail of the apical portion of the nasus showing the four larger sensory hairs among differently-sized hairs, in addition to rather conspicuous glandular pores (arrows) (scale bar $=0.1 \mathrm{~mm})$. (C) Detail of the pores $(\mathrm{p})$ and a bell-shaped sensillum (scale bar $=5 \mu \mathrm{m}$ ).

nal foraging behaviors (Mathews, 1977). According to Baker et al. (1981), at the time when the workers return to the nest with the food, the soldiers guard open trails of foraging workers with their mandibles opened and their heads roosed. This soldier position is defensive, and given that this soldier is a mandibulate nasute, it seems to use both mechanical (mandibles) and chemical defense (frontal gland secretion).

Noirot and Darlington (2000) argued that many species of Termitidae lack specialized characters for the ejection of the secretion, and, thus, its use remains conjectural. This seems not to be the case of Syntermes, in which the chemical secretion of the frontal gland has already been identified and consists mainly of a terpenoid compound (cis- $\beta$-ocimene), which is toxic when applied topically on ants (Howse, 1984).

The morphological pattern shown by the frontal gland of Syntermes has already been described for soldiers of other species of Nasutitermitinae, such as Cornitermes and Armitermes (Costa-Leonardo, 1998, 2001; Costa-Leonardo and De Salvo, 1987; Quennedey, 1984). This morphological pattern can be described as
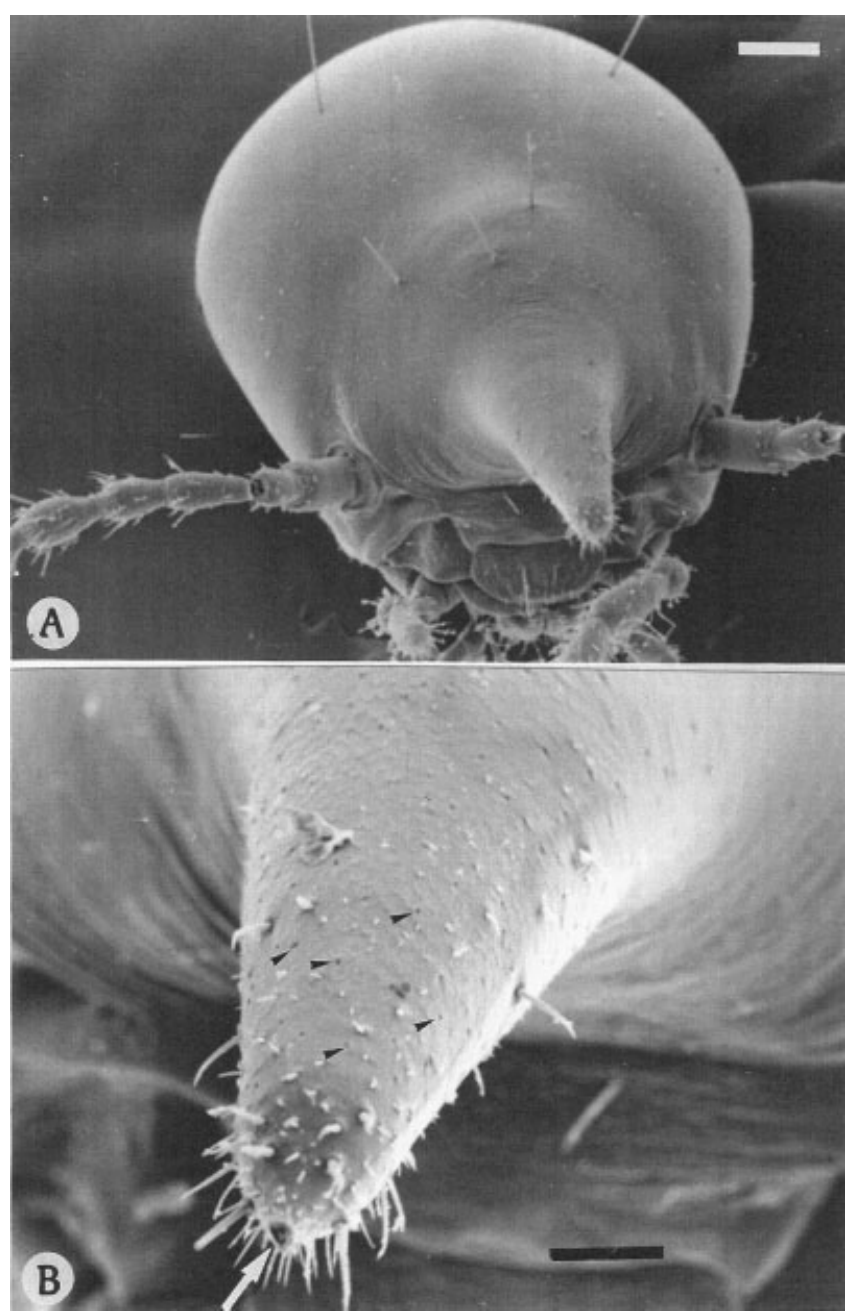

Fig. 5. (A) Head of a large soldier of $V$. heteropterus (scale bar $=$ $50 \mu \mathrm{m}$ ). (B) Detail of the frontal tube (nasus). The arrow indicates the frontal pore and the arrowheads show the glandular pores scattered on the nasus among the sensory hairs (scale bar $=25 \mu \mathrm{m}$ ).

sac-shaped, lacking a glandular neck, and the associated musculature consists of short fibers that are not connected to the integument. The brush border has already been described in glandular cells of other termite soldiers and its main function is to increase the area used for the elimination of the secretion.

The frontal gland of $C$. cyphergaster follows the pattern found in other nasute termites with atrophied mandibles, such as Nasutitermes, Velocitermes, and Trinervitermes (Costa-Leonardo, 1992; Costa-Leonardo and De Salvo, 1987; Quennedey, 1984). The presence of an epithelium composed by class I cells at the base of the gland and a well developed muscle layer that is connected to the integument are always characteristics of this structural pattern of the frontal gland. The existence of a glandular neck that ends at the posterior half of the cephalic capsule and opens into a wide reservoir, as well as the presence of pores on the external integument of the frontal tube are additional characteristics of these nasute termites.

Transmission electron microscopy (TEM) revealed the presence of class III cells distributed over the fron- 

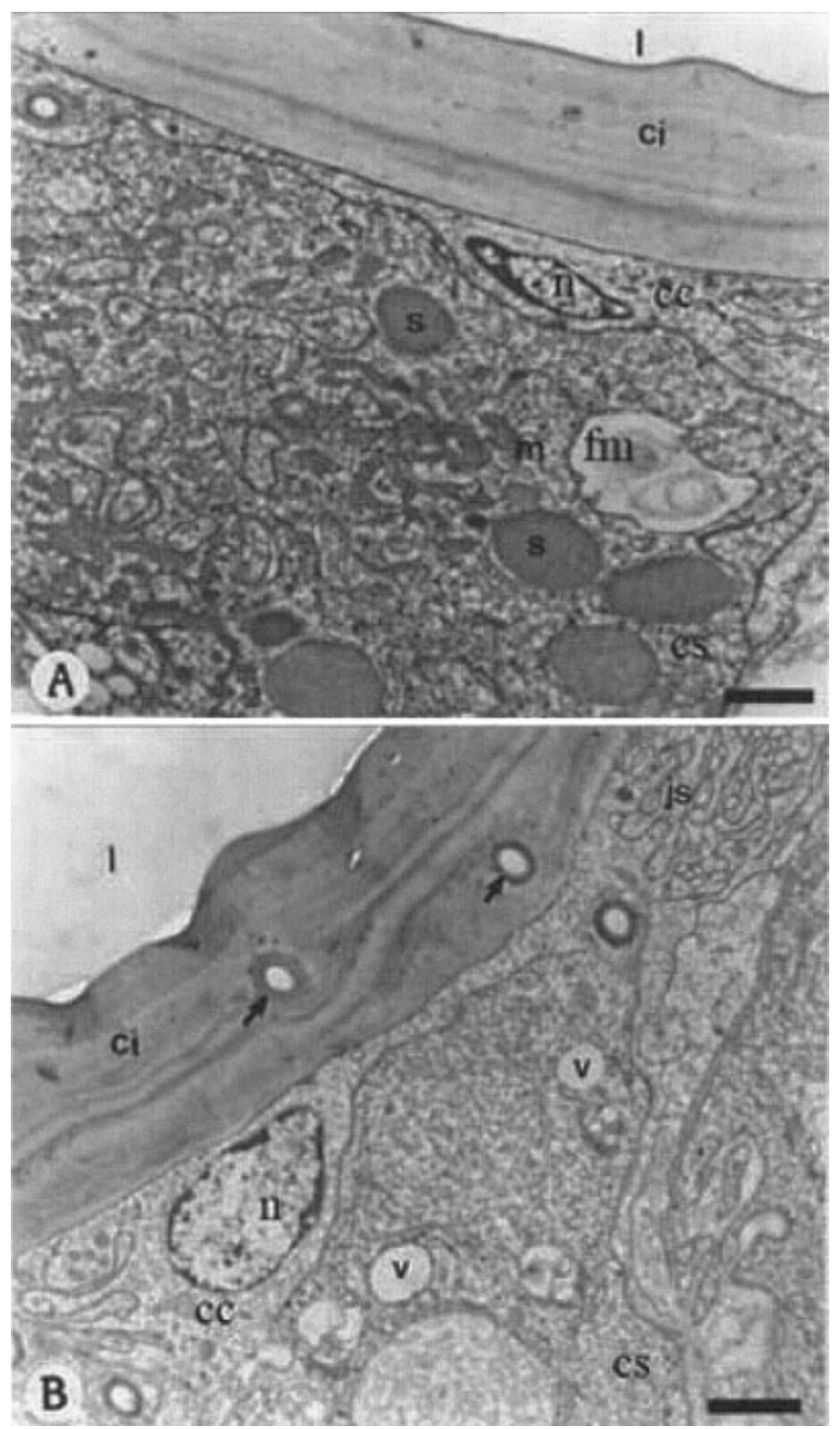

Fig. 6. (A) Transverse section of the frontal tube of a large soldier of $V$. heteropterus. Note a glandular cell containing electron dense secretory vesicles (s) and mitochondria (m); ci, internal cuticle; l, lumen of the frontal tube (scale bar $=1 \mu \mathrm{m}$ ). (B) Transverse section of the frontal tube of a large soldier of $V$. heteropterus. Note the cuticular channels (arrows) of the type III cells crossing the internal cuticle (ci) in order to release the secretion inside the lumen. Note the presence of vesicles (v) with vacuolar appearance. js, septate junctions; l, lumen of the frontal tube (scale bar $=1 \mu \mathrm{m}$ ).

tal tube of the full nasutes (Fig. 6), and also that the secretory product of these cells must be an important component of the final secretion of the frontal gland of these soldiers, given that this product is discharged directly into the lumen of the frontal tube. Quennedey (1984) also found this same glandular morphology in soldiers of Trinervitermes; however, Prestwich (1983) reported the presence of different mixtures of terpenes in the frontal gland of the both types of soldiers found in this genus. Nevertheless, the morphology of the frontal gland shown in the present study for both small and large soldiers of $N$. corniger was identical to the one reported previously, as well as for the three types of soldiers found in Velocitermes.
In general, the secretion produced by soldiers of the genus Nasutitermes is a sort of glue composed by diterpenes in a monoterpene solvent (Prestwich, 1979). Baker et al. (1984) isolated a trinervitane from the frontal gland of $C$. cyphergaster. According to Prestwich (1983), there is a great variety of chemical compounds produced by the frontal glands of soldiers of the Nasutitermitinae.

In the termites examined, the frontal pore was always located at the apex of the frontal tube. In Syntermes, the secretion seems to drip from the nasus aided by an intrinsic musculature. On the other hand, in Constrictotermes, Nasutitermes, and Velocitermes, the opening of the tube is narrow and the viscous secretion is ejected by the contraction of an extrinsic musculature. Chapman (1998) defines a visceral musculature as extrinsic when it originates from the wall of the insect's body and intrinsic when it is only associated to the organ in question (i.e., the frontal gland) and lacks a connection with the body wall.

Several types of sensory hairs are associated to the frontal pore (Deligne et al., 1981). There are hundreds of hairs surrounding the frontal opening of Cornitermes cumulans (Costa-Leonardo, 1998). Nevertheless, Quennedey (1984) found only four larger hairs surrounding the frontal pore of Trinervitermes, such as the ones described in the present study for Velocitermes. Campaniform sensilla have already been described on the labrum of some soldiers of the family Rhinotermitidae and on the frontal tube of Spinitermes brevicornutus and Embiratermes festeivellus (CostaLeonardo and Barsotti, 1996). According to Deligne et al. (1981), both the sensory hairs and the sensilla must provide data concerning the distortion of the integumental cuticle when the soldiers are in contact with enemies, thus playing a role in mechanoreception. Noirot and Darlington (2000) emphasized that a high proportion of soldiers seems to be found in the genera of termites that show a well-developed chemical defense system, such as the genus Nasutitermes.

\section{ACKNOWLEDGMENTS}

The authors thank CNPq (Conselho Nacional de Desenvolvimento Científico e Tecnológico) for financial support.

\section{REFERENCES}

Baker R, Coles HR, Edwards M, Evans DA, Howse PE, Walmsley S. 1981. Chemical composition of the frontal gland secretion of Syntermes soldiers (Isoptera, Termitidae). J Chem Ecol 7:135-145.

Baker R, Organ AJ, Prout K, Jones R. 1984. Isolation of a novel triacetoxysecotrinervitane from the termite Constrictotermes cyphergaster (Termitidae, subfamily Nasutitermitinae). Tetra Lett 25:579-580.

Billen J, Morgan ED. 1998. Pheromone communication in social insects: Sources and secretions. In: Vander Meer RK, Breed MD, Espelie KE, Winston ML, editors. Pheromone communication in social insects: Ants, wasps, bees, and termites. London: Westview Press. pp. 3-33.

Chapman RF. 1998. The insects: Structure and function, 4th ed. Cambridge: Cambridge University Press. 770 pp.

Constantino R. 1999. Chave ilustrada para identificação dos gêneros de cupins (Insecta: Isoptera) que ocorrem no. Brasil Pap Avulsos Zool 40:387-448.

Costa-Leonardo AM. 1992. The secretory epithelium of the frontal gland in Velocitermes sp. soldiers (Isoptera, Termitidae). Naturalia (São Paulo) 17:99-109.

Costa-Leonardo AM. 1998. Morphology of the frontal weapon in the soldier caste of Cornitermes cumulans (Isoptera, Termitidae). Rev Bras Entomol (São Paulo) 41:195-197. 
Costa-Leonardo AM. 2001. The frontal weapon of the termite Armitermes euamignathus Silvestri (Isoptera, Termitidae, Nasutitermitinae). Rev Bras Zool (Curitiba) 18:411-419.

Costa-Leonardo AM, Barsotti RC. 1996. Soldier head morphology of the neotropical termites: Embiratermes festivellus Silvestri and Spinitermes brevicornutus (Desneux) (Isoptera, Termitidae). Rev Bras Zool 13:321-330.

Costa-Leonardo AM, De Salvo CR. 1987. A comparative study of the frontal glands in three species of Brazilian termite soldiers (Isoptera, Termitidae). Rev Bras Entomol 31:465-471.

Deligne J, Quennedey A, Blum MS. 1981. The enemies and defense mechanisms of termites. In: Hermann HR, editor. Social insects, Vol. 2. New York: Academic Press. pp. 1-67.

Fontes LRO. 1987. Cupins Neotropicais da subfamília Nasutitermitinae (Isoptera. Termitidae): Morfologia do soldado e das mandíbulas do alado e operário, antomia do tubo digestivo do operário e filogenia dos gêneros. Tese (Doutor). Instituto de Biociências. Universidade Estadual Paulista. $141 \mathrm{pp}$.

Grassé PP. 1986. Termitologia: Anatomie, Physiologie, Biologie, Systématique des termites, Vol. 3. Paris: Masson. 715 pp.

Howse PE. 1984. Sociochemicals of termites. In: Bell WJ, Cardé RT, editors. Chemical ecology of insects. New York: Chapman and Hall. pp. $475-519$

Kriston I, Watson JAL, Eisner T. 1977. Non-combative behaviour of large soldiers of Nasutitermes exitiosus (Hill): An analytical study. Insectes Soc 24:103-111.

Mathews AGA. 1977. Studies on termites from Mato grosso State Brasil. Academia Brasileira de Ciências, Rio de Janeiro, Brazil. $267 \mathrm{pp}$.

Mcmahan EA. 1974. Non-aggressive behavior in large soldier of Nasutitermes-exitiosus (Hill) (Isoptera, Termitidae). Insectes Soc 21:95-106.
Mcmahan EA, Watson JAL. 1975. Nonreproductive castes and their development in Nasutitermes-exitiosus (Hill) (Isoptera). Insectes Soc 22:183-197.

Miura T, Matsumoto T. 2000. Soldier morphogenesis in a nasute termite: Dicovery of disc-like structure forming a soldier nasus. Proc $\mathrm{R}$ Soc Lond B Biol Sci 267:1185-1189.

Noirot CH. 1969. Glands and secretions. In: Krishna K, Weesner FM, editors. Biology of termites, Vol 1. New York: Academic Press. pp. 89-123.

Noirot C, Darlington JPEC. 2000. Termite nests: Architecture, regulation and defence. In: Abe T, Bignell DE, Higashi M, editors. Termites: Evolution, sociality, symbioses, ecology. Dordrecht: Kluwer. pp. 121139.

Noirot C, Quennedey A. 1974. Fine structure of insect epidermal glands. Annu Rev Entomol 19:61-80.

Noirot C, Quennedey A. 1991. Glands, gland cells, glandular units: Some comments on terminology and classification. Annu Soc Entomol Fr 27:123-128.

Prestwich GD. 1979. Chemical defense by termite soldiers. J Chem Ecol 5:459-480.

Prestwich GD. 1983. Chemical systematics of termite exocrine secretions. Annu Rev Ecol Syst 14:287-311.

Prestwich GD. 1988. The chemicals of termites societies. Sociobiology 14:175-191.

Quennedey A. 1984. Morphology and ultrastructure of termite defense glands. In: Hermann HR, editor. Defensive mechanisms in social insects. New York: Praeger Scientific. pp. 151-200.

Roisin Y. 2000. Diversity end evolution of caste patterns. In: Abe T, Bignell DE, Higashi M, editors. Termites: Evolution, sociality, symbioses, ecology. Dordrecht: Kluwer. pp. 95-119.

Traniello JFA, Beshers SN. 1985. Species-specific alarm recruitment responses in a neotropical termite. Naturwissenschaften 72:491-492. 